\title{
Preface
}

\section{Chiara Pollaroli}

Institute of Argumentation Linguistics and Semiotics

USI - Università della Svizzera italiana

Via Giuseppe Buffi 13 - 6900 Lugano

Switzerland

sara.greco@usi.ch

\section{SARA Greco}

Institute of Argumentation Linguistics and Semiotics

USI - Università della Svizzera italiana

Via Giuseppe Buffi 13 - 6900 Lugano

Switzerland

chiara.pollaroli@usi.ch

\section{Steve OsWaLd}

Department of English

University of Fribourg

Avenue de l'Europe 20, 1700 Fribourg

Switzerland

steve.oswald@unifr.ch

\section{JOHANNA MIECZNIKOWSKI-FUENFSCHILLING}

Institute of Italian Studies \& Institute of Argumentation Linguistics and Semiotics

USI - Università della Svizzera italiana

Via Giuseppe Buffi 13 - 6900 Lugano

Switzerland

Johanna.miecznikowskifuenfschilling@usi.ch

\section{ANDREA RocCI}

Institute of Argumentation Linguistics and Semiotics

USI - Università della Svizzera italiana

Via Giuseppe Buffi 13 - 6900 Lugano

Switzerland

andrea.rocci@usi.ch 


\section{Focusing the topic}

The topics of "rhetoric" and "language" are so vast that dealing with them in one special issue is quite challenging. Discussing rhetoric and language entails discussing the practice of situated persuasive communication and its use of a communication system which is recursive, discrete, structure-dependent and which is shared within a community as a means of communication and of context change. A lot on our plate. And even if we limit the topics to "emotions" and "style," much still needs to be covered. Such an investigation requires that we address one of the three rhetorical appeals-pathos - that does not always receive the attention it deserves in argumentation studies (cf. for example Gilbert 2001; Macagno and Walton 2014) and the issue of elocutio- "wording" or "style"- which, in the past centuries, has been narrowed down to the study of figuration and often restricted to the study of metaphor only. So, emotion and style might be overlooked and sentenced to be rhetorical aspects which are not at the core of a discourse and thus not rightfully at the core of argumentative investigation. Or even worse: Jacobs (2000, p. 275) grumbles at those who consider appeals to emotions as a load that "shuts down in an audience critical scrutiny of the issues" and who cage it into "a kind of irrelevant contribution that distracts an audience from factual considerations" with the result that if pathos is "not condemned outright, the reader is warned to view [it] with deep suspicion." As for style and rhetorical strategies, they might be lamentably dismissed as mere violations of ideals of argumentative discourse (as noted by Jacobs 2006, p. 42) or their analyses might result in observations that spill over without any focal point because of a lack of proper focus on what style is (van Eemeren 2019, p. 153).

Luckily, this is not the case for most scholars interested in rhetoric and argumentation. Scholars would hardly deny that the topical potential of a message works hand in hand with audience demand and presentational devices to balance an argumentative contribution both rhetorically and dialectically (van Eemeren 2010; framing presentational devices as style and audience demand as pathos is suggested in Fahnestock 2009, p. 211). Notably, 
there is a longstanding tradition of study of the relevance of emotions in discourse and argumentation, which has been flourishing in particular in the French speaking area (Kerbrat-Orecchioni 1999, 2000; Plantin 2011; Cigada 2006, 2008; Micheli 2013, 2014; Serafis and Herman 2018). These authors often work on political or public discourse (see for example Cigada 2008 on public speeches that contributed to the foundation of a united European community after WWII), highlighting the importance of emotions in argumentative discourse and their reasonableness (Plantin 1988); they also draw a distinction between emotions that are linguistically expressed and emotions that are implied or argued for (Micheli 2014).

Going back to the origins, Aristotle, in the first book of Rhetoric, already highlights the importance of "putting the audience into a certain frame of mind" and teaches that "persuasion may come through the hearers, when the speech stirs their emotions. Our judgements when we are pleased and friendly are not the same as when we are pained and hostile." In Bitzer's (1968) terms, in order to engage the audience in a rhetorical situation through a rhetorical discourse and to ask them to become a "mediator of change" (Bitzer 1968, p. 4) and to alter an "exigence" (p. 6) into a better reality, the audience needs to be captured "in thought and action" (p. 4). Adherence of the audience's heart (Rigotti and Cigada 2013, p. 15) and mind is a reasonable path to achieve intellectual contact and secure the audience's cooperation for the argument to develop (Perelman and Olbrechts-Tyteca 1969 [1958], pp. 14-18). Besides, "emotional appeals can play a constructive role in deliberation and may be positively required by the situation" (Jacobs 2000, p. 277). This is particularly true for those situations "where an audience does not take seriously the urgency or moral gravity of the problems addressed by an advocate but they should. Under these circumstances effective emotional appeals may not degrade the deliberative capacities of an audience; they may enhance them" (Jacobs 2000, p. 277). A similar view is held by Plantin (2011, p. 210), who argues that emotions orientate reason but do not annihilate it; according to him, emotions do not hinder the capacity that reason has to judge what is true and evident and to put these judgments in a chain of reasoning. Moving to a multi-

(C) Chiara Pollaroli. Informal Logic, Vol. 39, No. 4 (2019), pp. 287-300 
modal display of emotions, the use of photographs, for example, might help the audience feel how a situation is "marked by urgency" (Bitzer 1968, p. 6) thanks to their ability to put the presence of an event in front of the eyes of the audience (Kjeldsen 2012). As Kjeldsen (2018, p. 63-75) observes, photographs of the dead body of the three-year old Syrian toddler Aylan Kurdi were published by media "urging action in order to stop suffering" (p. 70) and thus contributed to a line of reasoning aimed at supporting the unbearability of the migration crisis.

In order to put the audience in a certain frame of mind and to be reasonably effective, various presentational devices are employed, which "contribute to (one could say constitute) any of the three appeals" (of rhetoric, i.e., ethos, pathos and logos) as Fahnestock (2009, p. 212) highlights. Surely, as the latter admits (2009, p. 193), "the subject of presentational devices is extremely complex" and must not be "limited to figuration", as a constrained view of rhetoric might suggest (Genette 1970). In fact, elocutio - the 'wording' of the persuasive address - is the category of rhetoric that is concerned with the "virtues of style," namely latinitas (correctness), perspicuitas (clarity), evidentia (evidence), aptum (propriety), and ornatus (ornateness). Figuration is specifically treated in ornatus. And even in this case figuration must not be confused with plain hollow embellishment, as a superficial addition to an already clear message with the only purpose of making it more fascinating and appealing. "Ornare" in the Latin language means 'to equip, fit out, or supply' and the Latin ornamentum means 'apparel, equipment [...] harness, collar [...] armour' (Plantin 2009). A soldier without his armour-without his ornamentum - is not a soldier anymore. Hence, "a well-ornamented discourse is a discourse well-equipped to fulfill its function" (Plantin 2009, p. 330).

Any presentational device in a discourse is carefully thought out and deliberately chosen (Fahnestock 1999) among a range of possibilities which are apt for one specific audience and rhetorical context in view of bringing about a sought-after communicative effect. If we were to explain to our students how "language choices [are] the levers of compromise" (Fahnestock 2009, p. 191) we would wisely make use of Fahnestock's example: the Camp David 
Accords elaborated in 1978 were the result of a large and complex revision of the language that the two chief parties involved, the Israeli Prime Minister Menachem Begin and the Egyptian President Anwar Sadat, would both sign. The two chief parties rarely met during the elaboration, which was largely based on shuttle mediation (Princen 1992), but twenty-three drafts were designed before both parties reached agreement on endorsing the same document. As Fahnestock highlights, "it is cases like this one that help students of argument appreciate the importance of presentation, of how things are worded in resolving differences."

Here we embrace a view of rhetoric as being "effective when people are empowered to make a reasonable decision" (Jacobs 2006 , p. 429) so that, when designing or analyzing a rhetorical intervention, the means by which this aim is achieved should be considered and chosen "functionally, not conventionally" and "situationally, and not just textually" in order to understand whether "the strategy improve[s] or degrade[s] the quality of reasoning and disputation relative to how it might otherwise proceed."

\section{Where this special issue comes from}

The present special issue includes a selection of papers which were presented during the second edition of the conference ARGAGE (Argumentation and Language-Argumentation et Langage) that took place in February 2018 at the Università della Svizzera italiana (Lugano, Switzerland). A selection of papers presented on that occasion were then peer-reviewed and updated for the present volume.

The aim of the conference was to explore the intersection between language (its units and functions) and the way argumentation works. Scholars were therefore asked to present papers related to at least one of the following five research tracks:

(1) argumentation co-constructed by two or more people in spoken interaction in institutional or informal contexts,

(2) the relation between semantic analysis and argumentation (exploring, for instance, the link between lexical mean- 
ing and norms/values in argumentation, or the relevance of semantic analysis to the normative assessment of reasoning), (3) the functioning of linguistic markers as indicators of argumentation,

(4) the retrieval of argumentatively relevant structures in texts and corpora and their manual or automatic annotation as well as the quantitative interpretation of annotaded data, (5) the use of rhetorical devices and figures of speech in argumentative practices and their effectiveness.

Needless to say, the present special issue collects papers which mostly address the 5 th research track. But the rhetorical approach on the interrelation between argumentation and language adopted by our contributors brought them to pay attention to some of the other tracks as well. In fact, this special issue contains papers on argumentation in dialogical interactions (both in online dialogues and in monological turns of broader dialogues), including spoken interaction, on the link between meaning choices and values and norms, on the manual annotation of corpora, as well as papers with attention to a quantitative interpretation of annotated data and to explicit markers of rhetorical contributions. As argumentative discourse is often developed through an interplay of communicative devices presented by means of linguistic and non-linguistic semiotic resources (e.g., text and image, speech and gestures together with facial expressions), attention is also given to multimodal rhetorical interventions. The method and integration of approaches constitute the most important aspects of the studies collected here; the methodological paths adopted are made explicit and methodological problems encountered are discussed with an eye to possible future developments of new methods. Besides, as the empirical data collected and analyzed in this collection of papers are complex and contextually situated, research questions are mostly answered by adopting perspectives coming from different analytical categories and perspectives. These multiple aspects offer new insights on the investigation of emotions and style that is at the core of each paper. 


\section{Overview of this special issue}

In his "Argumentative strategies and stylistic devices," Ton van Haaften gives methodological advice for a systematic and comprehensive analysis of argumentative strategies and stylistic devices in argumentative discourse. By defining an argumentative strategy as a coordinated and coherent set of strategic manoeuvres put forward in argumentative discourse to achieve a goal both dialectically and rhetorically, and by assuming that argumentative strategies are context-dependent and can be manifested consistently in discourse or in only one stage of a critical discussion, van Haaften presents, step by step and through a case study, his 'linguistic-stylistic analysis' method integrated within a general framework of pragma-dialectical analysis of argumentation. Analysts need to be well-equipped with background knowledge to apply this method. Firstly, argumentative discourse should be reconstructed in an analytical overview and the stages of a critical discussion (in pragma-dialectical terms) should be identified together with their dialectical and rhetorical aims. Secondly, a checklist of linguistic and stylistic categories should be adopted in order to systematically identify those employed - or not employed!-within discourse (van Haaften provides a ready-to-use example of a checklist in the appendix to his paper, but he warns that a checklist of this kind could never be exhaustive otherwise it would be unmanageable). This step of the analysis combines with another step in which the effect of the devices chosen is determined on the basis of semantic and pragmatic analysis. Thirdly and finally, the presence of coordinated stylistic choices must be checked within each discussion stage and in the discourse as a whole. However, van Haaften concludes, even if one adopts this systematic method, the analysis of argumentative strategies does not become less complicated.

While van Haaften illustrates his method by analyzing a discourse by the Dutch MP Geert Wilders, leader of a populist political party known for its strategic use of extremist discourse, Andrea Balbo, in his paper "Old delivery and modern demagogy. How ancient oratorical style and delivery can help us to understand modern populist speakers," presents an investigation on the actio 
and elocutio of oratoria popularis in ancient rhetoric and its comparison to modern populism. The advantage of a comparison of this kind comes from the fact that learning more about ancient communicative practices might help our knowledge and understanding of modern communication. Unfortunately, as Balbo admits, this study is made more difficult by the difference in data availability; on the one side, the multimodality of modern populist speeches is easily accessible everywhere, on the other side, we can only rely on the descriptions of ancient speeches provided by rhetorical or grammatical works to get knowledge on how they were delivered. Despite this empirical problem, similarities between ancient and modern delivery can be found; bitterness, forcefulness, and sharpness in style, use of pathetic elements to support or contrast arguments, expressive violence, exaggerations, screams, proximity to people's problems and dramas, etc. are frequent in both cases. Two examples from the ancient world are given: the Gracchi and Clodius. Speaking of contemporary authors, the analysis of US President Trump's interventions as examples of populistic speeches is enriched with a comparison with Obama's style and way of approaching the public.

Vehement ways of presenting one's viewpoint are also of interest for Christian Plantin, who, in his paper "Tense Arguments. Rhetorical questions, exclamations, emotions," illustrates tense arguments with the study of a polemical online contribution with strong anti-Semitic undertones. Tension as an operation of high involvement is explained through a detailed analysis of the case study. Plantin shows how the controversial text is characterized by radical arguments, exclamations, rhetorical questions, and emotions which represent rhetorical choices that mimic face-to-face interactions, that do not leave room for counter-arguments but rather challenge the opponents' voices, and that allow the speakers to assert both the truth of their propositional content and the high degree of the expression. The degree of tension in the example provided is high from the beginning, but its intensity rises with the development of the text. In other words, the arguments selected (thus a choice from inventio) together with exclamations, lexical choices and rhetorical questions (thus choices from elocutio) make the emotion rise throughout the text. Plantin shows that tension is 
a veridictive operator, meaning that it changes the argument from 'true in my opinion' to 'true as far as my argument is good' turning it into just 'true' at the end of the message. The audience is not free to engage in a critical scrutiny of the proponent's argument and is trapped in an interaction where challenging the tensed claim amounts to challenging the person physically. Not quite what rhetoric aims at.

A not very felicitous use of this rhetorical appeal (pathos) is also illustrated by Thierry Herman and Dimitris Serafis in their paper "Emotions, argumentation and argumentativity: Insights from an analysis of newspapers headlines in the context of the Greek crisis." Herman and Serafis present a methodologicallyoriented study of implicit argumentation in newspaper headlines. As the argumentativity of headlines per se might not be straightforwardly accepted, the authors argue in detail that headlines are able to suggest standpoints even without explicitly offering arguments to support them. The selection of data is central: among the 50 headlines analyzed, the authors include a detailed account of two headlines offered by Greek newspapers from opposite orientations. Moreover, the selected headlines contribute to the already polarized social context of the Greek crisis by arousing emotions and by making the audience perceive the urgency of the rhetorical situation. A description of the meaning of the headlines through a systemic functional analysis, an analysis of the semiotization of the rhetorical pathos to trace emotions in headlines, together with an argumentative reconstruction following the Argumentum Model of Topics provide a synergic approach to detect emotions and their rhetorical effects of enforcing the premises and paving the way to the conclusion in argumentation.

Just like newspaper headlines are not the most straightforward example of argumentation, so is narration. Yet, this makes their rhetorical purpose even more interesting to detect besides the fact that these are single instances of a broader point of contention which includes other instances of discourse. As Herman and Serafis's headlines, Sara Cigada's analyzed narrative excerpt (a monologue) should be understood within the dialogue process (the discussion) it belongs to; in fact, the video-recording that constitutes Cigada's empirical corpus is part of a project aimed at acti-

(C) Chiara Pollaroli. Informal Logic, Vol. 39, No. 4 (2019), pp. 287-300 
vating dialogue on an educational issue. In her paper "Emotions in argumentative narration. The case of the Charlie Hebdo attack," Cigada reconstructs the argumentative role that emotions have in an autobiographical narration by a Lebanese French-speaking schoolteacher who is speaking about how the Charlie Hebdo attack affected her students. By starting from Plantin's and Micheli's accounts of emotions in discourse and by combining them with Pragma-Dialectics and the Argumentum Model of Topics, Cigada shows how emotional inferencing happens, that is how emotions work as inferential triggers for argumentation. Language structures containing or hinting at emotions can thus work as arguments for an action to be undertaken (or not) or as implicit standpoints starting from a factual premise reporting an event (in this case, the attack on the Charlie Hebdo premises) that reasonably causes an emotion. Moreover, attention to the narrator's stylistic choices of mitigation enables one to understand the difference between what she reports and her personal position on the issue, making it possible to see how polyphonic discourse develops within a dialogical interaction.

Again, at face-value, putting forward arguments to support a claim is not a feature we expect to find in conduct books either, but Annick Paternoster, in her "Emotive figures as 'shown' emotion in Italian post-unification conduct books (1860-1900)," shows us that conduct books can actually be very argumentative. In conduct books, the exposition of the social norms is often interrupted with passages which exhibit emotive discourse and style to engage the audience and persuade them that the instructions are grounded on moral values. Paternoster's contribution presents a research based on a collection of a wide corpus and annotated with UAM Corpus Tool. Text mining and analysis go hand in hand: after emotive figures are tagged and identified into clusters, the author illustrates how emotive clusters ("shown" emotions) trigger moving values, that is, values which argumentatively serve to support an emotion ("argued" emotion). Paternoster's findings confirm the contextual dependency of persuasive discourse; personal values related to self-improvement, diligence and parsimony attract more emotive clusters and thus are the most employed values to ground an argument. So, at the time of Italian post- 
unification, conduct books were rhetorical interventions that contributed to the whole social discourse and persuaded citizens to be part of the building of a nation by claiming that people, with their personal efforts, could be active in this construction. The exemplified list of rhetorical figures that Paternoster provides enriches very well the checklist van Haaften includes in his paper; and these two contributions could thus be considered as complementary methodological options.

Education, which we have already encountered in Cigada's and Paternoster's papers, albeit under different aspects, is also the communicative context to which Kati Hannken-Illjes \& Ines Bose's paper "Frozen: Children in argumentation between the agonistic and cooperation" belongs. By combining a conversationanalytic and ethnographic perspective to an approach to argumentation that considers it as embedded in every interaction, the authors study face-to-face confrontations among preschoolers on a building task in order to identify which elements frame the interaction as cooperative or agonal. The different framing of the interaction is established through the use of different sources, i.e. through the oral verbal means as well as through vocal tones and body movements, showing that these semiotic resources function in integration one with the other. Moments of freezing (stasis) happen in agonal interactions but they are solved. Surprisingly, these are not solved through argumentative exchanges on the issue but through the introduction of a new thematic focus. Thus, in the interactions described, children's cooperation might not be found in single issues but rather in the overall framing of the interaction, that is the play, which must go on anyway.

Moving to a different context, but remaining within the realm of rhetorical argumentation, the interplay of different semiotic modes is at work in the advertisements and commercials analyzed in the paper "The rhetorical and argumentative relevance of "extreme consequence' in advertising" by Sabrina Mazzali-Lurati, Chiara Pollaroli \& Daniela Marcantonio. The selected empirical cases present instances of what has been identified as the "extreme consequences" template, a pattern quite common in advertising, which tries to persuade on the worth of a product by showing an (extreme) odd result of using the product. The hyperbolic repre-

(C) Chiara Pollaroli. Informal Logic, Vol. 39, No. 4 (2019), pp. 287-300 
sentations of effect-to-cause structures are analyzed through an integration of Conceptual Integration Theory (or Blending Theory) and the Argumentum Model of Topics. These two perspectives enable one to make explicit the mental spaces and operations activated when interpreting these types of ads and the argumentative-inferential path activated with the advertising logos as well as to understand their rhetorical impact on the interpreter. The analyses proposed in this paper show that the 'extreme consequence' pattern corresponds to an argumentative line of reasoning of the final-instrumental type (means-end argumentation), which can be activated by a collaborative audience willing to solve the initial puzzlement.

\section{Acknowledgment}

We are thankful to the authors, who engaged in both contributing with their studies and in reviewing other contributors' papers. We are also grateful to external reviewers who offered their time and expertise to make this special issue possible. Finally, we are grateful to the Swiss National Science Foundation (grant IZSEZ0_179145 applicant: Sara Greco) and to the Swiss Society of Applied Linguistics (VALS-ALSA), which generously contributed to the funding of the 2018 edition of the ARGAGE conference, which is at the origin of this special issue.

\section{References}

Aristotle, Rhetoric. Translation by W. Rhys Roberts. Available online www.bocc.ubi.pt.

Bitzer, Lloyd. 1968. The rhetorical situation. Philosophy and Rhetoric 1: $1-14$.

Cigada, Sara. 2006. Connectif et relation entre locuteurs. Application à l'analyse d'un corpus de presse politique sur la question européenne («Le monde», 11 mai 1950). In Sýndesmoi. Connettivi nella realtà dei testi, eds. Giovanni Gobber, Maria C. Gatti and Sara Cigada, 97173. Milano: Vita e Pensiero.

Cigada, Sara. 2008. Les émotions dans le discours de la construction européenne. Milano: ISU. 
Van Eemeren, Frans H. 2010. Strategic maneuvering in argumentative discourse: Extending the pragma-dialectical theory of argumentation. Amsterdam: John Benjamins.

Van Eemeren, Frans H. 2019. Argumentative style: A complex notion. Argumentation 33(2): 153-171.

Fahnestock, Jeanne. 1999. Rhetorical figures in science. New York: Oxford University Press.

Fahnestock, Jeanne. 2009. Quid pro nobis. Rhetorical stylistics for argument analysis. In Examining argumentation in context. Fifteen studies on strategic maneuvering, ed. Frans H. van Eemeren, 131152. Amsterdam: John Benjamins.

Genette, Gerard. 1970. La rhétorique restreinte. Communications 16: $158-171$.

Gilbert, Michael A. 2001. Emotional messages. Argumentation 15(3): 239-250.

Jacobs, Scott. 2000. Rhetoric and dialectic from the standpoint of normative pragmatics. Argumentation 14: 261-286.

Jacobs, Scott. 2006. Nonfallacious rhetorical strategies: Lyndon Johnson's Daisy ad. Argumentation 20(4): 421-442.

Kerbrat-Orecchioni, Catherine. 1999. L'énonciation. De la subjectivité dans le langage. Paris: Armand Colin.

Kerbrat-Orecchioni, Catherine. 2000. Quelle place pour les émotions dans la linguistique $\mathrm{du} \mathrm{xx}^{\mathrm{e}}$ siècle ? Remarques et aperçus. In Les emotions dans les interactions, ed. Christian Plantin et al., 33-74. Lione: PUL.

Kjeldsen, Jens. E. 2012. Pictorial argumentation in advertising: visual tropes and figures as a way of creating visual argumentation. In Topical themes in argumentation theory. Twenty exploratory studies, eds. Frans H. van Eemeren and Bart Garssen, 239-255. New York: Springer.

Kjeldsen, Jens E. 2018. The rhetorical and argumentative potentials of press photography. In Multimodal argumentation and rhetoric in media genres, eds. Assimakis Tseronis and Charles Forceville, 51-80. Amsterdam: John Benjamins.

Macagno, Fabrizio and Douglas Walton. 2014. Emotive language in argumentation. Cambridge: Cambridge University Press.

Micheli, Raphael. 2013. Esquisse d'une typologie des différents modes de sémiotisation verbale de l'émotion. In Modes de sémiotisation et fonctions argumentatives des émotions, eds. Raphä̈l Micheli, Ida Hekmat and Alain Rabatel, 17-39. Besançon: Presses Universitaires de Franche-Compté. 
Micheli, Raphael. 2014. Les émotions dans le discours. Modèle d'analyse, perspectives empiriques. Louvain-la-Neuve: De Boeck.

Perelman, Chaim, and Lucie Olbrechts-Tyteca. 1969. The new rhetoric: A treatise on argumentation. Notre Dame, Indiana: University of Notre Dame Press. [1958. Traité de l'argumentation: la nouvelle rhétorique. Bruxelles: Université de Bruxelles.]

Plantin, Christian. 1998. Les raisons des émotions. In Forms of Argumentative Discourse, ed. Marina Bondi, 3-50. Bologna: CLUEB.

Plantin, Christian. 2011. Les bonnes raisons des émotions. Bern: Peter Lang.

Plantin, Christian. 2009. A place for figures of speech in argumentation theory. Argumentation 23: 325-337.

Princen, Thomas. 1992. Intermediaries in International Conflict. Princeton, NJ: Princeton University Press.

Rigotti, Eddo, and Sara Cigada. 2013. La comunicazione verbale. Second edition. Ravenna (Italy): Maggioli editore. 